\title{
The effect of the octahedral cations on the dimensions of the palygorskite cell
}

\author{
M. SUÁREZ ${ }^{1}$, E. GARCÍA-ROMERO², M. SÁNCHEZ DEL RÍOº \\ P. MARTINETTO ${ }^{4}$ AND E. DOORYHÉE ${ }^{4}$
}

\begin{abstract}
${ }^{1}$ Departamento de Geología, Universidad de Salamanca, 37008 Salamanca, Spain, ${ }^{2}$ Departamento de Cristalografia y Mineralogía, Universidad Complutense de Madrid, 28040 Madrid, Spain, ${ }^{3}$ European Synchrotron Radiation Facility, BP 22038043 Grenoble Cedex, France, and ${ }^{4}$ Institut Néel, Grenoble BP 166, F-38042 Grenoble Cedex 09, France
\end{abstract}

(Received 11 October 2006; revised 9 March 2007)

\begin{abstract}
High-resolution synchrotron X-ray diffraction recorded on a collection of palygorskites with different chemical compositions (obtained by analytical electron microscopy) permits unambiguous correlation of the crystallographic parameters $a$ (or $a \sin \beta$ if a monoclinic phase is considered) with the nature of the octahedral sheet, i.e. with both the number of octahedral positions that are occupied and the type of octahedral cation. No significant changes in the lattice parameters $b$ and $c$ are observed. The unit cell modification consists essentially of an expansion in $a$ as the number of cations with larger ionic radii $\left(\mathrm{Mg}^{2+}\right.$ and $\left.\mathrm{Fe}^{3+}\right)$ predominates over smaller cations $\left(\mathrm{Al}^{3+}\right)$. A linear dependency of $a$ (or $a \sin \beta$ ) on the chemical composition of the octahedral sheet was obtained that can be used for classifying palygorskite into compositional groups, using only conventional diffraction data, without the need for chemical analyses.
\end{abstract}

KEYWORDS: palygorskite, synchrotron, X-ray diffraction, transmission electron microscopy.

The structure of palygorskite contains ribbons of 2:1 phyllosilicates linked by periodical inversion of the apical oxygen of the continuous tetrahedral sheet. Therefore, the octahedral sheet is discontinuous (Fig. 1). Bradley (1940) proposed the first structural model for palygorskite and suggested that the mineral has a $\mathrm{Si}_{8} \mathrm{Mg}_{5} \mathrm{O}_{20}(\mathrm{OH})_{2}\left(\mathrm{OH}_{2}\right)_{4} \cdot 4 \mathrm{H}_{2} \mathrm{O}$ formula. This author concluded that palygorskite is monoclinic, with a probable space group $C 2 / \mathrm{m}$. Later, Drits \& Alexandrova (1966) published a review on the chemical analyses of palygorskites concluding that, in most cases, only four of each five octahedral positions can be occupied. Therefore they suggested a dioctahedral model as opposed to the trioctahedral model postulated by Bradley. The

* E-mail: msuarez@usal.es

DOI: 10.1180/claymin.2007.042.3.02 dioctahedral model, with structural formula $\mathrm{Si}_{8}\left(\mathrm{Mg}_{2} \mathrm{Al}_{2}\right) \mathrm{O}_{20}(\mathrm{OH})_{2}\left(\mathrm{OH}_{2}\right)_{4} \cdot 4 \mathrm{H}_{2} \mathrm{O}$, where the central atomic position in the octahedral sheet is empty, was also confirmed by Drits \& Sokolova (1971), Mifsud et al. (1978) and Serna et al. (1977).

Güven et al. (1992) proposed a restricted distribution of the octahedral cations along the ribbon. With respect to the ideal composition, $M 1$ is vacant, $M 2$ is occupied by $\mathrm{Mg}$ and $M 3$ is occupied by Al. Suárez \& García-Romero (2006b) agreed with this and showed that in most palygorskites $\mathrm{Mg}>\left({ }^{\mathrm{VI}} \mathrm{Al}+\mathrm{Fe}^{3+}\right)$ and isomorphic substitution in the octahedral sheet $\left({ }^{\mathrm{VI}} \mathrm{Al}\right.$ by $\mathrm{Mg}$ ) occurs only in the $M 2$ position. $\mathrm{Al}$ and $\mathrm{Fe}$ may occupy the $M 2$ position, whereas $\mathrm{Mg}$ can occupy all possible sites: $M 1, M 2$ and $M 3$.

There are three studies that compare powder diffraction results on a series of palygorskites. Chirst et al. (1969) and Chisholm (1990, 1992) related the differences found between several 


\section{a}

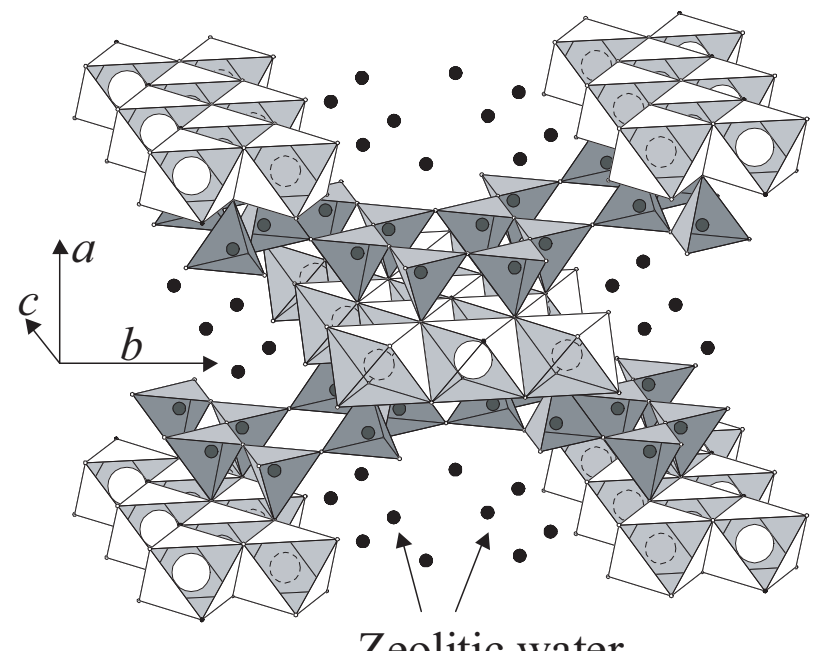

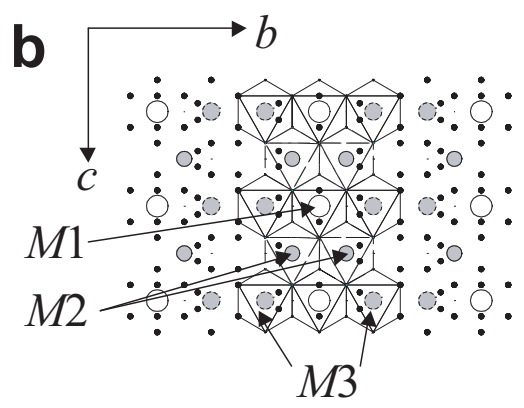

C

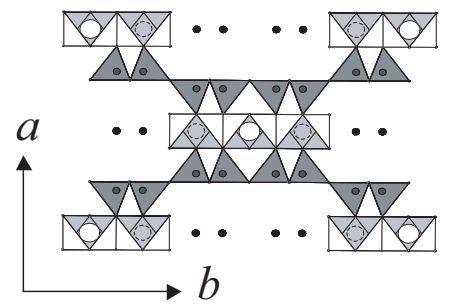

FIG. 1. Structural scheme for palygorskite: (a) perspective view; (b) projection onto the $(b, c)$ plane; and (c) projection onto the $(a, b)$ plane.

samples to different ratios of two phases: one monoclinic and the other orthorhombic, corresponding to $C 2 / m$ and $P b m n$ space groups, respectively.

Few studies include a crystallographic refinement for palygorskite. Using synchrotron radiation, Artioli \& Galli (1994) and Artioli et al. (1994) studied an Italian palygorskite from Bolca, but full Rietveld refinement was not achieved. Chiari et al. (2003) performed Rietveld refinement on synchrotron radiation data from a Mexican palygorskite from Yucatan. Giustetto \& Chiari (2004) used neutron data to refine the structure of the same Mexican palygorskite. In all these studies, no chemical analyses were performed and the stoichiometry of palygorskite was assumed to be that of the ideal model.

Regarding the chemical composition of palygorskite, Galán \& Carretero (1999) affirmed that palygorskite contains mainly $\mathrm{Mg}, \mathrm{Al}$ and $\mathrm{Fe}^{3+}$ with an $R^{2+} / R^{3+}$ ratio close to 1 . García-Romero et al. (2004) reported a palygorskite very rich in $\mathrm{Mg}$ which is compared with palygorskites from other origins and with the bibliographic data. They verified that in all palygorskites the $\mathrm{Al}$ content is smaller than the Mg content in the octahedral sheet, even though the ratio $R^{3+}$ to $\mathrm{Mg}$ is close to 1 , because of the presence of $\mathrm{Fe}^{3+}$ in most samples.
Both Chirst et al. (1969) and Chisholm (1992) pointed out that the variations in symmetry can reflect variations in chemical composition, but did not provide any evidence. In this paper we present an experimental study showing how the chemical composition of this mineral does in fact affect its structure. In particular, the diffraction patterns reveal some variations of the unit cell dimensions as a function of the octahedral content.

\section{EXPERIMENT A L}

\section{Materials}

Eight palygorskite samples from different origins are studied here, including some minerals much discussed in the literature, such as that from Attapulgus. The names used in this work and the geographical origin of the samples follows: LIL, a palygorskite featuring laminar texture, from the Lisbon volcanic complex (Portugal); BER, from Bercimuel (Segovia, Spain); YUC, from Ticul (State of Yucatán, Mexico), BOT, a palygorskite with botryoidal texture, also from the Lisbon volcanic complex; TOR, from Torrejón el Rubio (Cáceres, Spain); ATT, from Attapulgus (USA); TRA, from Los Trancos (Almería, Spain), and ESQ, from Esquivias (Madrid, Spain). 
All samples were of high purity, checked by mineralogical characterization performed by X-ray diffraction (XRD) with a laboratory source. Small impurities of quartz were detected in ATT, BER, TOR and ESQ samples. Also, small amounts of smectites were found in the ATT sample and calcite in TOR. Most of the samples have been characterized and analysed previously (García-Romero et al., 2004, 2006; Suárez \& García Romero, 2006a,b)

\section{Methods}

To obtain the structural formula of palygorskite, standard methods of chemical analysis should be avoided because they measure an average value of the elements over the sample. Therefore, the unavoidable presence of impurities, usually containing elements of the same type as palygorskite, introduces errors. A microcharacterization using analytical electron microscopy (AEM) with transmission electron microscopy (TEM), permits a selective analysis on selected palygorskite fibres to be performed. This analysis is repeated on a number of fibres from the same sample in order to obtain values that statistically represent the palygorskite in the macroscopic sample. A JEOL 2000 FX microscope was used, equipped with a double-tilt sample holder (up to a maximum of $\pm 45^{\circ}$ ). It was operated at an acceleration voltage of $200 \mathrm{kV}$, with $0.5 \mathrm{~mm}$ zeta-axis displacement and $0.31 \mathrm{~nm}$ point-to-point resolution. The microscope incorporates an OXFORD ISIS energy dispersive X-ray spectrometer (136 eV resolution at $5.39 \mathrm{keV}$ ) and has its own software for quantitative analysis. The validity of the $\mathrm{K}$-factors employed in the calculation of concentrations from the fluorescence intensities was double-checked, first using a reference (synthetic hectorite, SynL-1), and secondly, benchmarking our results with bibliographic data on some well studied palygorskites: Attapulgus (Georgia, USA), Yucatán (Mexico) and Torrejón el Rubio (Cáceres, Spain). The structural formulae for the palygorskites were calculated from the ideal structure, normalized to 42 negative charges. Oxygen was not measured quantitatively. All the Fe present was considered as $\mathrm{Fe}^{3+}$, thus ignoring the possible existence of $\mathrm{Fe}^{2+}$ (usually very small), which cannot be discriminated by this analytical technique. The same microscope was used for obtaining SAED (selected area electron diffraction) images on selected fibres.

High-resolution powder XRD patterns were collected at beamline BM01B of the SwissNorwegian $\mathrm{CRG}$ at the European Synchrotron
Radiation Facility (ESRF, Grenoble) with a fixed wavelength of $0.79950 \pm 0.00001 \AA$ (calibrated using a silicon powder standard) at room temperature. Powdered samples were placed inside a $1 \mathrm{~mm}$ diameter capillary, which was rotated during exposure. Data collection was performed in a continuous $2 \theta$-scan mode from $3^{\circ}$ to $28^{\circ}$.

\section{RESULTS}

\section{Chemical composition}

The chemical composition of the samples was obtained using TEM point analysis on individual palygorskite particles. The resulting chemical formulae are shown in Table 1. The tetrahedral substitution in these natural palygorskites is very low $(0.02-0.15)$, i.e. $<0.5 \mathrm{Al}$ atoms for eight tetrahedral sites. This is in agreement with the data reported previously by Galán \& Carretero (1999). Indeed, some palygorskite samples do not present any tetrahedral substitution (LIL and TRA).

The atomic contents of the octahedral sheet vary from one sample to another, both for the total occupation number OC $(3.96 \leqslant \mathrm{OC} \leqslant 4.35)$ and for the atomic type. The sample with formula closest to the theoretical one is LIL, showing an $R^{2+} / R^{3+}$ ratio very close to 1 with almost no $\mathrm{Fe}^{3+}$. BER also has an $R^{2+} / R^{3+}$ ratio very close to 1 but with a large $\mathrm{Fe}^{3+}$ content. The composition in the octahedral sheet is anomalous with respect to the theoretical formula in TRA and ESQ. They are very rich in $\mathrm{Mg}$ : thus always having an $R^{2+} / R^{3+}$ ratio $>2$. The rest of the samples (YUC, BOT, TOR and ATT) present similar composition, with $1.22 \leqslant$ $R^{2+} / R^{3+} \leqslant 1.34$.

\section{High-resolution synchrotron powder diffraction.}

The recorded XRD patterns for the eight palygorskites are shown in Fig. 2. Some differences can be observed in peak shape, intensity and position of some peaks. The differences in the peak width are related to the different crystallinity and particle size of the samples. The peaks are quite broad because palygorskite, like all clay minerals, presents small grains of the order of $1 \mu \mathrm{m}$ or less in size; thus the crystallites inside the grains are even smaller. The differences in the intensity could be caused by a number of things, including the proportion of the orthorhombic and monoclinic 
TABLE 1. Chemical content of the eight palygorskites, obtained by AEM. Presented for each sample are: the number of atoms corresponding to general structural formula $\mathrm{Si}_{8} \mathrm{O}_{20} \mathrm{M}_{5}\left(\mathrm{OH}_{2}\right)_{2} \cdot 4 \mathrm{H}_{2} \mathrm{O}$, the relationship between divalent and trivalent octahedral cations $\left(R^{2+} / R^{3+}\right)$ and the number of octahedral positions occupied per half unit cell (OC). The quoted error values correspond to one standard deviation.

\begin{tabular}{lccccccccccc}
\hline Sample & $\mathrm{Si}$ & ${ }^{\mathrm{IV}} \mathrm{Al}$ & ${ }^{\mathrm{VI}} \mathrm{Al}$ & $\mathrm{Mg}$ & $\mathrm{Fe}^{3+}$ & $\mathrm{Ca}$ & $\mathrm{K}$ & $\mathrm{Na}$ & $R^{2+} / R^{3+}$ & $\mathrm{OC}$ \\
\hline \multirow{2}{*}{ LIL } & 8.02 & 0.00 & 1.91 & 2.01 & 0.04 & 0.01 & - & 0.07 & 1.03 & 3.96 \\
& $( \pm 0.04)$ & $( \pm 0.01)$ & $( \pm 0.05)$ & $( \pm 0.08)$ & $( \pm 0.02)$ & $( \pm 0.01)$ & & $( \pm 0.09)$ & $( \pm 0.05)$ & $( \pm 0.08)$ \\
BER & 7.90 & 0.10 & 1.60 & 1.98 & 0.39 & 0.05 & 0.04 & - & 0.99 & 3.97 \\
& $( \pm 0.12)$ & $( \pm 0.07)$ & $( \pm 0.20)$ & $( \pm 0.25)$ & $( \pm 0.04)$ & $( \pm 0.02)$ & $( \pm 0.03)$ & & $( \pm 0.22)$ & $( \pm 0.11)$ \\
YUC & 7.85 & 0.15 & 1.57 & 2.21 & 0.24 & 0.03 & 0.11 & 0.00 & 1.22 & 4.02 \\
& $( \pm 0.13)$ & $( \pm 0.12)$ & $( \pm 0.20)$ & $( \pm 0.22)$ & $( \pm 0.05)$ & $( \pm 0.02)$ & $( \pm 0.10)$ & $( \pm 0.01)$ & $( \pm 0.25)$ & $( \pm 0.13)$ \\
BOT & 7.98 & 0.02 & 1.61 & 2.27 & 0.16 & 0.02 & - & 0.05 & 1.28 & 4.04 \\
& $( \pm 0.06)$ & $( \pm 0.05)$ & $( \pm 0.06)$ & $( \pm 0.09)$ & $( \pm 0.01)$ & $( \pm 0.01)$ & & $( \pm 0.04)$ & $( \pm 0.09)$ & $( \pm 0.05)$ \\
TOR & 7.91 & 0.09 & 1.48 & 2.25 & 0.37 & 0.01 & 0.02 & - & 1.22 & 4.10 \\
& $( \pm 0.07)$ & $( \pm 0.05)$ & $( \pm 0.06)$ & $( \pm 0.06)$ & $( \pm 0.04)$ & $( \pm 0.01)$ & $( \pm 0.02)$ & & $( \pm 0.06)$ & $( \pm 0.03)$ \\
ATT & 7.85 & 0.15 & 1.47 & 2.30 & 0.25 & 0.08 & 0.05 & 0.07 & 1.34 & 4.02 \\
& $( \pm 0.07)$ & $( \pm 0.07)$ & $( \pm 0.07)$ & $( \pm 0.16)$ & $( \pm 0.04)$ & $( \pm 0.03)$ & $( \pm 0.03)$ & $( \pm 0.08)$ & $( \pm 0.17)$ & $( \pm 0.13)$ \\
TRA & 8.02 & 0.00 & 1.20 & 2.89 & 0.16 & 0.01 & 0.01 & - & 2.13 & 4.25 \\
& $( \pm 0.04)$ & $( \pm 0.02)$ & $( \pm 0.09)$ & $( \pm 0.11)$ & $( \pm 0.03)$ & $( \pm 0.00)$ & $( \pm 0.01)$ & & $( \pm 0.19)$ & $( \pm 0.07)$ \\
ESQ & 7.87 & 0.13 & 1.04 & 3.11 & 0.20 & 0.02 & 0.05 & 0.08 & 2.51 & 4.35 \\
& $( \pm 0.09)$ & $( \pm 0.09)$ & $( \pm 0.11)$ & $( \pm 0.26)$ & $( \pm 0.06)$ & $( \pm 0.03)$ & $( \pm 0.03)$ & $( \pm 0.09)$ & $( \pm 0.65)$ & $( \pm 0.11)$
\end{tabular}

phases in each sample (Chisholm 1990, 1992). The variations in the position of some peaks reveal changes in the cell parameters from one sample to another. Due to the low symmetry of palygorskite, most peaks observed in the XRD pattern correspond to several overlapping reflections. Only a few peaks can be related to individual reflections. This is the case for the 110,200 and 040 reflections, corresponding to $d$ spacings of 10.4-10.6, 6.34-6.46 and 4.46-4.47 $\mathrm{A}$, respectively. Table 2

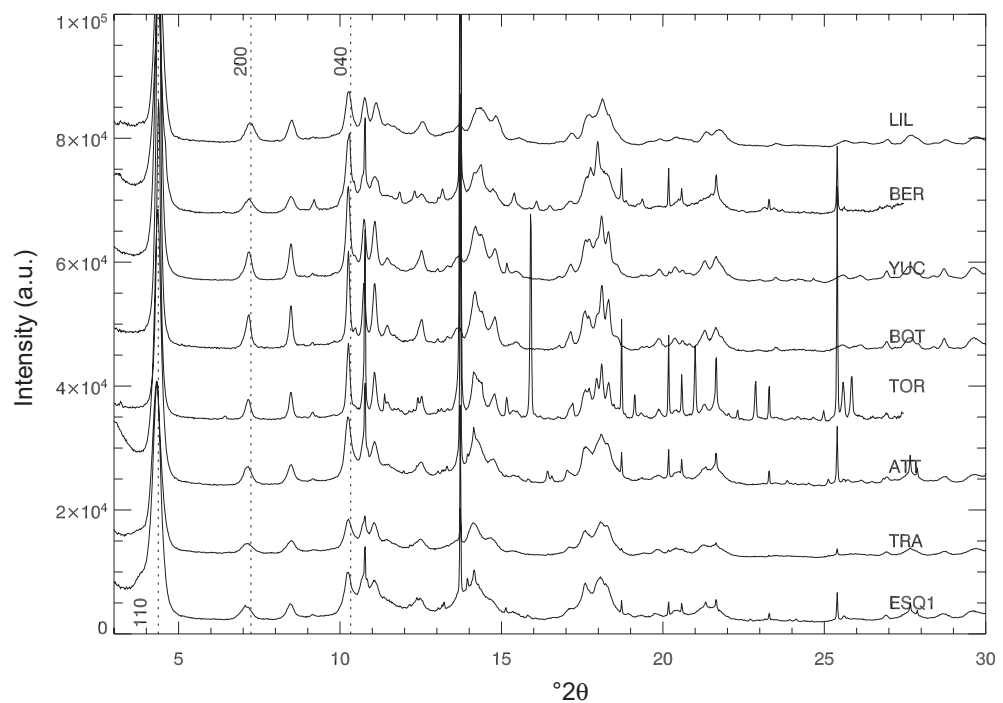

FIG. 2. Synchrotron XRD patterns for the eight palygorskite samples studied. Photon wavelength is 0.8 A. Dotted lines indicate the approximate positions of the 110, 200 and 040 peaks, which are discussed in the text. 
TABLE 2. $d$ spacings and cell parameters calculated from the peak position of three non-overlapping reflections from synchrotron XRD patterns $(\AA)$. The peak position was computed as the centre of a pseudo-Voigt function fitted to the experimental peak profile.

\begin{tabular}{lccccc}
\hline Sample & $d_{110}$ & $d_{200}$ & $d_{040}$ & $a$ or $a \sin \beta=2 d_{200}$ & $b=4 d_{040}$ \\
\hline LIL & 10.464 & 6.349 & 4.469 & 12.699 & 17.875 \\
BER & 10.493 & 6.388 & 4.470 & 12.776 & 17.879 \\
YUC & 10.471 & 6.387 & 4.474 & 12.774 & 17.897 \\
BOT & 10.464 & 6.396 & 4.472 & 12.793 & 17.887 \\
TOR & 10.461 & 6.407 & 4.472 & 12.814 & 17.890 \\
ATT & 10.525 & 6.421 & 4.476 & 12.842 & 17.903 \\
TRA & 10.613 & 6.430 & 4.473 & 12.861 & 17.894 \\
ESQ & 10.584 & 6.465 & 4.480 & 12.929 & 17.918 \\
\hline
\end{tabular}

contains the $d$ spacing values calculated from the peak position of these selected reflections for all samples studied.

\section{DISCUSSION}

Using the reflections listed in Table 2 it is possible to obtain information about the $a$ and $b$ parameters for both monoclinic and orthorhombic phases. The most important differences are found in the positions of the 110 and 200 peaks. We use the 200 reflection to calculate the values of the $a$ parameter (if an orthorhombic phase is considered) or $a \sin \beta$ (monoclinic). The $b$ parameter is calculated directly from the 040 reflection. Due to the fact that palygorskite is presented in the form of fibres oriented along the $c$ direction, the intensities in the recorded XRD patterns are biased by this preferred orientation. Moreover, information on the 001 reflections cannot be directly extracted from the diffractogram, and we used electron diffraction data for discussing changes in this direction. However, it is not possible to obtain the values for $c$ as accurately as those for $a$ and $b$ because of the much lower resolution of this technique as compared to our XRD data.

There is no discussion in the literature on the different $d$ spacing for a given reflection that could be produced by the two overlapped structures (monoclinic and orthorhombic). The relative proportion of the different phases does not produce differences in peak positions (Chisholm, 1992; Chiari et al., 2003). Therefore, for the following discussion we consider that both possible structures, if they co-exist, present the same $b$ and $c$ unit-cell parameter, and $a \sin \beta$ in the monoclinic structure is equivalent to $a$ in the orthorhombic phase. Consequently, most of the changes in peak positions (or cell parameters) must originate from changes in composition.

Comparing the compositional and structural results (Tables 1 and 2, respectively), it is observed that the most Mg-rich samples present the highest $d$ spacing for the reflections under consideration. More precisely, the variations found in composition of the octahedral sheet in palygorskite samples are related to the changes in the structural parameters by applying a statistical treatment. Table 3 presents the correlation matrix among these data. High correlation values are observed, meaning that there is a high interdependence among these parameters. The chemical effect on the structure is discussed independently for the $a, b$ and $c$ lattice dimensions.

\section{Effect of the octahedral cations on the a lattice parameter}

When looking at the $d$ spacing of the 200 reflections (i.e. $a$ for the orthorhombic phase, and $a \sin \beta$ for the monoclinic phase), one observes a correlation (Table 3) with OC, i.e. the number of octahedral positions occupied (correlation coefficient: $\mathrm{CC}=0.876)$, and with the $\mathrm{Mg}$ content $(\mathrm{CC}=$ $0.885)$. However, the best correlation found $(\mathrm{CC}=$ $-0.973)$ is inverse with $\left[{ }^{\mathrm{VI}} \mathrm{Al}\right]$. The direct correlation value with the $\left[\mathrm{Mg}+\mathrm{Fe}^{3+}\right]$ contents is also high (0.956) but a little lower than the $\left[{ }^{\mathrm{VI}} \mathrm{Al}\right]$. This means that the nature of cations does in fact influence the $a$ cell dimension: the $d$ spacing along the $a$ axis increases when $\left[{ }^{\mathrm{VI}} \mathrm{Al}\right]$ decreases. This effect is more important than the dioctahedral 
TABLE 3. Correlation matrix (correlation coefficients, CC) of chemical data (from AEM, Table 1) and structural data (from synchrotron XRD, Table 2).

\begin{tabular}{|c|c|c|c|c|c|c|c|c|c|}
\hline & $d_{110}$ & $a$ & $b$ & {$\left[{ }^{\mathrm{VI}} \mathrm{Al}\right]$} & {$\left[\mathrm{Fe}^{3+}\right]$} & [Mg] & {$\left[\mathrm{Al}+\mathrm{Fe}^{3+}\right]$} & {$\left[\mathrm{Mg}+\mathrm{Fe}^{3+}\right]$} & $\mathrm{OC}$ \\
\hline$d_{110}$ & 1.000 & 0.776 & 0.605 & -0.836 & -0.151 & 0.870 & -0.887 & 0.841 & 0.810 \\
\hline$a$ & & 1.000 & 0.884 & -0.973 & 0.194 & 0.885 & -0.875 & 0.956 & 0.876 \\
\hline$b$ & & & 1.000 & -0.836 & 0.054 & 0.791 & -0.800 & 0.820 & 0.750 \\
\hline$\left[{ }^{\mathrm{VI}} \mathrm{Al}\right]$ & & & & 1.000 & -0.177 & -0.925 & 0.909 & -0.991 & -0.927 \\
\hline$\left[\mathrm{Fe}^{3+}\right]$ & & & & & 1.000 & -0.200 & 0.250 & 0.085 & -0.095 \\
\hline$[\mathrm{Mg}]$ & & & & & & 1.000 & -0.994 & 0.959 & 0.979 \\
\hline$\left[\mathrm{Al}+\mathrm{Fe}^{3+}\right]$ & & & & & & & 1.000 & -0.939 & -0.952 \\
\hline$\left[\mathrm{Mg}+\mathrm{Fe}^{3+}\right]$ & & & & & & & & 1.000 & 0.968 \\
\hline $\mathrm{OC}$ & & & & & & & & & 1.000 \\
\hline
\end{tabular}

character (i.e. the number of octahedral vacancies $\mathrm{OV}=5-\mathrm{OC})$. The key point in explaining these differences is the size of the ionic radius of the cations. $\mathrm{Mg}^{2+}$ and $\mathrm{Fe}^{3+}$ (of 0.72 and $0.64 \AA$ ionic radii, respectively) are larger than $\mathrm{Al}^{3+}(0.54 \AA)$; therefore they contribute to a greater deformation of the octahedral sheet and, consequently, to an expansion of the 2:1 layer. This effect is well known for other phyllosilicates (Newman \& Brown, 1987). For example, the $d$ spacing for the 001 reflection varies between $9.20 \AA$ (pyrophyllite) and $9.33 \AA$ (talc), which correspond to the pure aluminic and magnesic minerals in the octahedral sheet, respectively. Recently, Cibin et al. (2006) studied structural changes in several micas induced by the adaptation of the tetrahedral sheets to the sizes of their octahedral sheets, which in turn depend on the chemical substitutions and on chemical changes at the octahedral anion site.

The value of the $d$ spacing along the $a$ axis increases as ${ }^{\mathrm{VI}} \mathrm{Al}$ content decreases, not only because $\mathrm{Al}$ is a smaller cation occupying octahedral positions, but also because more Al in octahedral positions implies a more dioctahedral character, thus with a larger number of vacancies (the correlation $\left[{ }^{\mathrm{VI}} \mathrm{Al}\right]$ to $\mathrm{OC}$ is $\left.\mathrm{CC}=-0.927\right)$. These two variables (more octahedral positions occupied and bigger cations) both contribute to increasing the $d$ spacing along $a$.

The $d$ spacing for the 200 reflection is a direct indicator of the aluminic vs. magnesic nature of the palygorskite. The equation of the weighted leastsquares linear fit (using errors from Table 1) is:

$\left[{ }^{\mathrm{VI}} \mathrm{Al}\right]=49.1617-7.4401 d_{200}, \quad R^{2}=0.951$

This result is represented in Fig. 3. It is possible to plot $d_{200}$ vs. the number of octahedral vacant sites $(\mathrm{OV})$, calculated from Table 1 as $\mathrm{OV}=5-\mathrm{OC}$. The equation of the linear fit is:

$\mathrm{OV}=24.0047-3.6065 d_{200}, \quad R^{2}=0.7678$

Note that the correlation of $d_{200}$ with $[\mathrm{Mg}+$ $\left.\mathrm{Fe}^{3+}\right]$ is also very high, and could also be included in the discussion. However, as $\left[\mathrm{Mg}+\mathrm{Fe}^{3+}\right]+\left[{ }^{\mathrm{VI}} \mathrm{Al}\right]$ $+\mathrm{O} . \mathrm{V} .=5$, this discussion would be redundant.

Furthermore, this dependency of the $a$ axis on $\left[{ }^{\mathrm{VI}} \mathrm{Al}\right]$ or $\left[\mathrm{Mg}+\mathrm{Fe}^{3+}\right]$ in palygorskite is consistent if we include sepiolite in the discussion. The sequence of atomic planes in the $a$-axis direction is the same in both minerals. Thus, the $d$ values in this direction should be the same if both minerals presented the same composition in the octahedral sheet (they do present the same composition in the tetrahedral sheet, completely filled by weakly substituted $\mathrm{Si}$, as discussed earlier). However, the $d$ spacing value for 100 (calculated from the theoretical structure) is $13.4 \AA$ for sepiolite and $12.7 \AA$ for the 'ideal' palygorskite (Jones \& Galán, 1988). This difference of $0.7 \AA$ in $d$ spacing corresponds to one unit cell (two octahedral sheets), and it is related to the fact that all the octahedral positions are occupied by $\mathrm{Mg}$ in sepiolite (Nagy \& Bradley, 1955), whereas only $2 / 5$ of the octahedral positions are occupied by this cation in the ideal palygorskite per half unit cell. If we assume that in an 'imaginary Mg-palygorskite' where the five octahedral positions per half unit cell are fully occupied by $\mathrm{Mg}$, the $d$ spacing of the 100 reflection would have the $d$ spacing of sepiolite. This value can be plotted together with the palygorskite points (Fig. 3). As can be seen, this $d$ spacing value for the 200 reflection corresponding to an 'imaginary trioctahedral magnesic-palygorskite' is consistent with the linear behavior of our experimental 


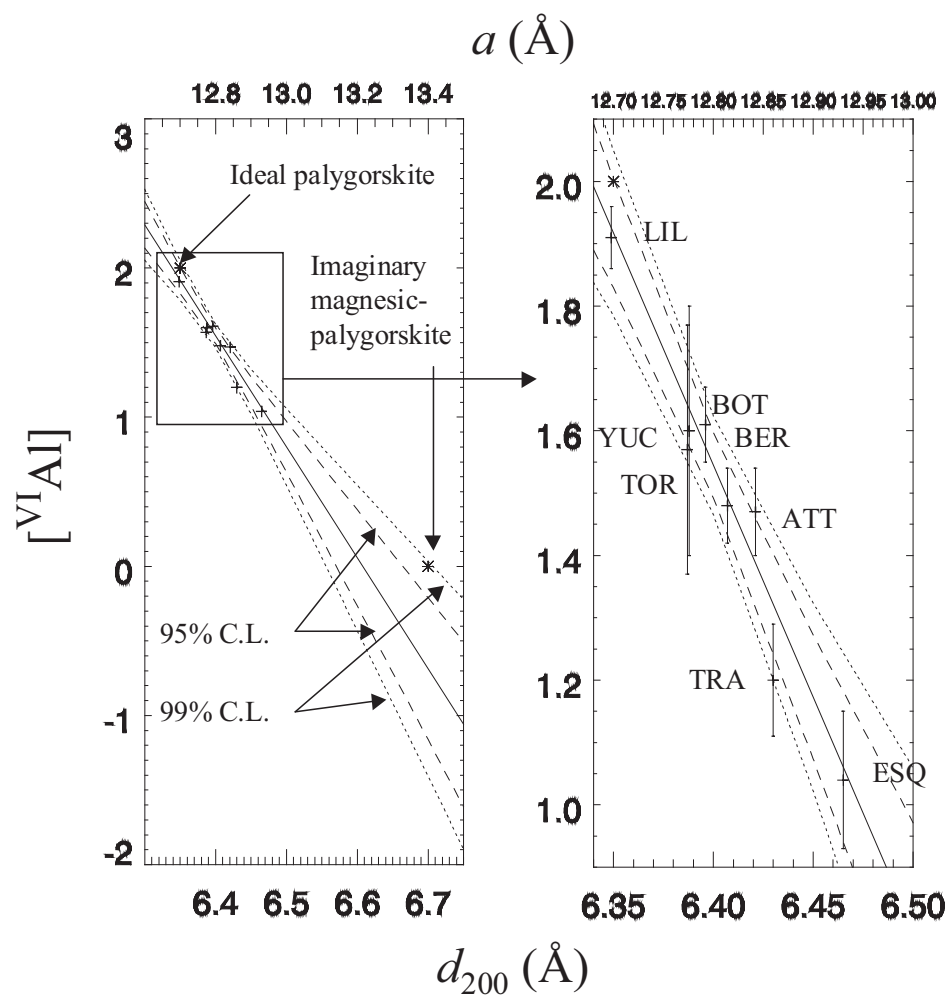

FIG. 3. Relationship between the number of $\mathrm{Al}$ ions occupying octahedral positions in palygorskites and the $d_{200}$ spacing (also $a$ or $a \sin \beta$ calculated from this reflection). Solid line: linear fit of equation 1, with the bands of confidence limits at 95\% confidence level (dashed) and 99\% confidence level (dotted). Left panel: The experimental points are plotted with the theoretical 'imaginary Mg-palygorskite' with five octahedral positions occupied by $\mathrm{Mg}$ and 'ideal palygorskite' (asterisks, see text). Right panel: detail showing the experimental points with the error bars (from Table 1).

palygorskite data, even though this point is in a zone where it is necessary to extrapolate the fitted straight line. Similarly, the predictions of equations 1 and 2 are also compatible with the 'ideal' palygorskite $\left(d_{200}=6.35 \AA\right)$. The $d_{200}$ values of these 'ideal' and 'imaginary Mg-palygorskite' could be used to postulate two theoretical linear dependencies, as in equations 1 and 2, giving $\left[{ }^{\mathrm{VI}} \mathrm{Al}\right]=38.2857-5.7143 d_{200}$ and $\mathrm{OV}=19.1428$ $-2.8571 d_{200}$. At first glance, these equations may look very different from our experimental fits (equations 1 and 2); however, they are compatible within three standard deviations of the linear fit coefficients.

Equations 1 and 2 could be useful to predict from the XRD pattern if a given palygorskite belongs to a certain compositional type, as will be discussed below.

\section{Compositional effects on the $b$ and c lattice parameters}

For phyllosilicates in general, the greater the occupancy of octahedral sites, the greater is $b$. This is frequently used to distinguish dioctahedral minerals from trioctahedral ones, i.e. by looking at the $0 k 0$ reflections of the XRD pattern (Moore et al., 1989). In our palygorskite samples, the greater $\mathrm{Mg}$ content corresponds to a higher trioctahedral character (i.e. higher octahedral occupancy). The $b$ cell parameter presents its highest correlation with respect to $\left[{ }^{\mathrm{VI}} \mathrm{Al}\right]$ (CC $=-0.836)$, as for $a$. This is also confirmed by the high correlation between $a$ and $b(\mathrm{CC}=0.884)$. However, $b$ ranges over a very narrow interval (17.87 $₫ \leqslant b \leqslant 17.89 \AA)$, thus showing the $b$ parameter to be less sensitive to chemical changes than is $a$. Thus the $b$ parameter is not a pertinent 
parameter to follow the chemical composition in palygorskite, at least within our experimental resolution.

The X-ray studies of powdered palygorskite do not provide information on the $c$ parameter because of the fibrous morphology of the particles, biasing the orientation of the unit cells in this direction. To overcome this difficulty, we compared electron diffraction images on individual fibres of the different palygorskites. In this configuration, the

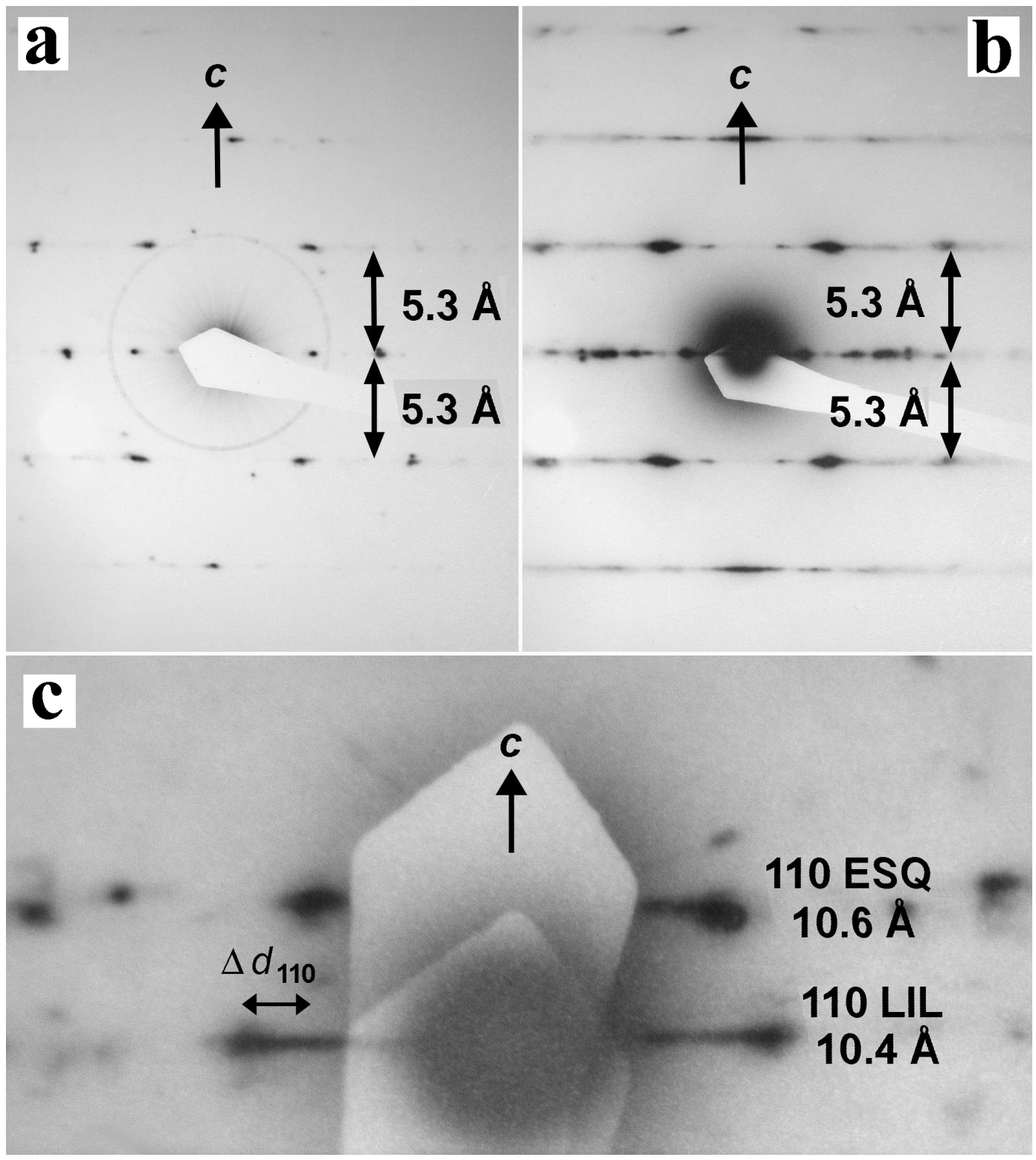

FIG. 4. Electron diffraction images corresponding to isolated laths of palygorskite: (a) ESQ sample and (b) LIL sample. Both images exhibit spots which permit measurement of $c$ at $\approx 5.3 \AA$. (c) Two superimposed images corresponding to LIL and ESQ samples. The difference in $d_{110}$ spacing can be appreciated for both samples, in good agreement with the synchrotron diffraction data. 
$c$ axis is normal to the incoming electron beam. Therefore it is possible to measure the $c$ parameter. In Fig. 4, the electron diffraction patterns corresponding to the LIL and ESQ samples are presented. The positions of the $00 l$ reflection $(l=$ $2 n$ ) coincide for both samples. Note, however, the much lower experimental resolution of these images compared with those of synchrotron XRD. To verify the sensitivity of the method, we compared the 110 reflection for both LIL and ESQ samples (the images are superposed in Fig. 4c). Here, the highest $d$ spacing corresponds to ESQ (magnesicpalygorskite) rather than to LIL, in good agreement with our XRD results. Thus, it can be concluded that the $c$ parameter $(\approx 5.3 \AA)$ is the same for the aluminic (LIL) and magnesic (ESQ) samples, or the differences are so small that they cannot be appreciated on these images.

\section{Classification of palygorskites using laboratory XRD}

The reproducibility of measured $d$ spacing depends on the instrument used: synchrotron radiation certainly gives more accuracy and perhaps more reproducibility than conventional sources. However, the natural variability of the composition in natural clays will produce slightly different $d$ spacings when the same material is measured several times. In our case, the samples studied by the three methods (AEM, conventional and synchrotron XRD) are not exactly the same, and there are some differences in $d$ spacings. A third source of variation is the software used for obtaining the $d_{200}$ values from the XRD patterns. We have obtained differences of the order of $0.008 \AA$ by using different software packages with different intervals for the peak-fitting routines. However, these uncertainties do not prevent use of equation 1 for separating and distinguishing between two palygorskites belonging to different groups using laboratory XRD data, even though quantitative compositional data inferred from equation 1 using $d_{200}$ from conventional XRD should be used with care. Another advantage of using XRD data for obtaining a quick compositional classification of palygorskites is the null sensitivity to impurities: clay minerals appear with impurities of other clays in most natural samples (sepiolite, smectite and illite are frequently found with palygorskite). These impurities cannot be separated by physical or chemical procedures. It is thus impossible to obtain the structural formulae of palygorskite from the chemical analyses of a bulk sample. The only way to obtain the structural formula in these cases is to perform AEM analyses, a facility not available in most laboratories.

We propose here a classification of palygorskite regarding its chemical composition and its relationship with $d_{200}$. It arises from the results presented in the past by Newman \& Brown (1987) and GarcíaRomero et al. (2004), and from a critical revision of chemical data for palygorskite in the literature. Palygorskites can be classified in three types:

(1) Palygorskite Type I or Aluminic-palygorskite: It is a dioctahedral extreme with similar contents of $\mathrm{Al}$ and $\mathrm{Mg}$ and therefore its structural formula is close to the ideal palygorskite $\mathrm{Si}_{8} \mathrm{O}_{20} \mathrm{Al}_{2} \mathrm{Mg}_{2} \square_{1}$ $(\mathrm{OH})_{2}\left(\mathrm{OH}_{2}\right)_{4} \cdot 4 \mathrm{H}_{2} \mathrm{O}$. Substitution of $\mathrm{Al}$ by $\mathrm{Fe}^{3+}$ is negligible and $\mathrm{Mg}+\mathrm{Fe}^{3+}=2$. When related to equation 1 , this type would correspond to $\left[{ }^{\mathrm{VI}} \mathrm{Al}\right]>$ 1.95 or $d_{200}<6.35 \AA$

(2) Palygorskite Type II: Its principal characteristics are: i) the $\left[{ }^{\mathrm{VI}} \mathrm{Al}\right]$ content is less than in the ideal formula, but exceeding one atom per molecule, and ii) the number of octahedral cations close to 4 (vacant octahedral postions $=1$ ). Although $\mathrm{Al}$ may be partially substituted by $\mathrm{Fe}^{3+}$ and/or $\mathrm{Mg}$, this type of palygorskite has dioctahedral character. Also, $2<\left[\mathrm{Mg}+\mathrm{Fe}^{3+}\right]<3$. When related to equation 1 , this type would correspond to $1.1<\left[{ }^{\mathrm{VI}} \mathrm{Al}\right]<1.95$ or $6.46>d_{200}>6.35 \AA$.

(3) Palygorskite Type III or Magnesic-palygorskite: It is the most trioctahedral extreme and therefore the number of octahedral cations is greater than 4 (vacant octahedral postions $<1$ ) because $\left[\mathrm{Mg}+\mathrm{Fe}^{3+}\right]$ $=3$. When using equation $1,\left[{ }^{\mathrm{VI}} \mathrm{Al}\right]<1.1$ or $d_{200}$ $>6.46 \AA$

Finally, we used equation 1 in order to classify palygorskites into these three groups using the $d_{200}$ values obtained from a conventional diffractometer. The same materials analysed with synchrotron XRD plus other two samples: ESQ2 (also from Esquivias) and SER (from the Serrata de Níjar, Almería, Spain). If conventional XRD data are compared with synchrotron data, there are some differences, as expected from the discussion above. Table 4 contains, in addition to the experimental values of $d_{200}$ (from conventional XRD), the ${ }^{\mathrm{VI}} \mathrm{Al}$ content and the number of vacant positions calculated using the two regression equations. As can be seen, the calculated data from conventional XRD using equations 1 and 2 are not far from those obtained uing AEM analyses for most samples. 
TABLE 4. Classification of palygorskites into three groups using conventional XRD (see text). The $d_{200}$ spacing is obtained from the $2 \theta$ value of the 200 peak in the diffractogram. The octahedral content is calculated by applying equations 1 and 2. The experimental AEM values are also shown for comparison.

\begin{tabular}{lccccccc}
\hline Sample & $2 \theta$ & $d_{200}$ & $\begin{array}{c}{\left[{ }^{\mathrm{VI}} \mathrm{Al}\right]} \\
\text { (equation } 1)\end{array}$ & $\begin{array}{c}\left.{ }^{\mathrm{VI}} \mathrm{Al}\right] \\
(\mathrm{AEM})\end{array}$ & $\begin{array}{c}\text { OV } \\
\text { (equation 2) }\end{array}$ & $\begin{array}{c}\text { OV } \\
(\mathrm{AEM})\end{array}$ & $\begin{array}{c}\text { Palygorskite } \\
\text { type }\end{array}$ \\
\hline LIL & 13.998 & 6.322 & 2.13 & 1.91 & 1.21 & 1.04 & $\mathrm{I}$ \\
SER & 13.950 & 6.343 & 1.97 & 1.93 & 1.13 & 1.07 & I \\
BER & 13.803 & 6.410 & 1.47 & 1.60 & 0.89 & 1.03 & II \\
YUC & 13.835 & 6.396 & 1.58 & 1.57 & 0.94 & 0.98 & II \\
BOT & 13.839 & 6.394 & 1.59 & 1.61 & 0.95 & 0.96 & II \\
TOR & 13.791 & 6.416 & 1.42 & 1.48 & 0.87 & 0.90 & II \\
ATT & 13.732 & 6.444 & 1.22 & 1.47 & 0.77 & 0.98 & II \\
TRA & 13.748 & 6.436 & 1.28 & 1.20 & 0.80 & 0.75 & II \\
ESQ & 13.626 & 6.493 & 0.85 & 1.04 & 0.59 & 0.65 & III \\
ESQ2 & 13.523 & 6.543 & 0.48 & 0.89 & 0.41 & 0.52 & III \\
Average & 13.784 & 6.420 & 1.40 & 1.47 & 0.85 & 0.89 &
\end{tabular}

\section{SUMMARY AND CONCLUSIONS}

Using high-resolution XRD, differences in the XRD patterns have been observed, not only in terms of the intensities but also in the position of the main reflections of palygorskite. These differences are related to the chemical composition of the samples, and a relationship between the type and occupancy of the octahedral sites and the cell parameters of palygorskite has been found. In palygorskite, $a$ (or $a \sin \beta$ ) and $b$ are greater when the octahedral $\mathrm{Al}$ content is less. A clear monotonous correlation is found for $a$, which varies from $12.70 \AA$ for Al-rich palygorskites to $12.93 \AA$ for Mg-rich palygorskites. The cell parameter $b$ variation is $<0.02 \AA$. Only small changes of this order or less in the $c$ axis may be expected, because no significant changes in the electron diffraction patterns were found.

The structure of palygorskite is influenced by both the nature and the amount (filling) of octahedral positions. Increasing the concentration of cations with larger ionic radii $\left(\mathrm{Mg}, \mathrm{Fe}^{3+}\right)$ with respect to $\mathrm{Al}$ produces an evident expansion (perhaps a distortion) in the $a$-axis direction.

By applying a linear equation (equation 2) to data measured by conventional XRD of powdered samples, it is possible to classify the palygorskite without any previous treatment of the samples into compositional groups. This is not affected by impurities, because the 200 reflection of palygorskite used does not overlap with any peak from usual impurities. Therefore, it is possible to estimate the octahedral content of a bulk sample containing impurities, with values even better than those obtained from chemical analysis.

\section{ACKNOWLEDGMENTS}

We acknowledge the ESRF for beamtime for this experiment, and the experimental staff of BM01B, in particular, D. Testemale. We also express our sincere thanks to Adrian Gómez Herrero from Centro de Microscopía Electrónica 'Luis Bru, (UCM)'. We also express our sincere thanks to Catherine Doyle for checking and improving the English. Financial support from the Spanish CICYT (project CGL2006-09843) and 'Servicio de Investigación de la UCM (Grupo 9103B6)' is also acknowledged.

\section{REFERENCES}

Artioli G. \& Galli E. (1994) The crystal structures of orthorombic and monoclinic palygorskite. Materials Science Forum, 166-169, 647-652.

Artioli G., Galli E., Burattini E., Cappuccio G. \& Simeoni S. (1994) Palygorskite from Bolca, Italy: a characterization by high-resolution synchrotron radiation powder diffraction and computerising modelling. Neues Jahrbuch für Mineralogie Monatshefte, 5, 217-229.

Bradley W.F. (1940) The structural scheme of attapulgite. American Mineralogist, 25, 405-411.

Chiari G., Giustetto R. \& Ricchiardi G. (2003) Crystal structure refinements of palygorskite and Maya Blue from molecular modelling and powder synchrotron diffraction. European Journal of Mineralogy, 15, 21-33.

Chirst C.L., Hathaway J.C., Hostler P.B. \& Shepard 
A.O. (1969) Palygorskite: New X-ray data. American Mineralogist, 54, 198-205.

Chisholm J.E. (1990) An X-ray powder-diffraction study of palygorskite. The Canadian Mineralogist, 28, 329-339.

Chisholm J.E. (1992) Powder-diffraction patterns and structural models for palygorskite. The Canadian Mineralogist, 30, 61-73.

Cibin G., Mottana A., Marcelli A. \& Brigatti M.F. (2006) Angular dependence of potassium K-edge XANES spectra of trictahedral micas: Significance for the determination of the local structure and electronic behaviour of the interlayer site. American Mineralogist, 91, 1150-1162.

Drits V.A. \& Alexandrova V.A. (1966) On the crystallographic nature of palygorskites. Zapiski Vsesoyuznogo Mineralogicheskogo Obshchestva, 95, 551-560.

Drits V.A. \& Sokolova G.V. (1971) Structure of palygorskite. Soviet Physics Crystallography, 16, $288-231$.

Galán E. \& Carretero I. (1999) A new approach to compositional limits for sepiolite and palygorskite. Clays and Clay Minerals, 47, 399-409.

García-Romero E., Suárez M. \& Bustillo M.A. (2004) Characteristics of a Mg-palygorskite in Miocene Rocks (Madrid Basin, Spain). Clays and Clay Minerals, 52, 486-496.

García-Romero E., Suárez M., Oyarzun R., LópezGarcía J.A. \& Regueiro M. (2006) Formation of palygorskite in secondary faults from a large shear zone of Miocene age (Serrata de Níjar, SE Spain). Clays and Clay Minerals, 54, 324-332.

Giustetto R. \& Chiari G. (2004) Crystal structure refinement of palygorskite from neutron powder diffraction. European Journal of Mineralogy, 16, $521-532$.

Güven N., Caillere J.P.E. \& Fripiat J.J. (1992) The coordination of aluminum ions in the palygorskite structure. Clays and Clay Minerals, 40, 457-461.

Jones B.F. \& Galán E. (1988) Sepiolite and palygorskite. Pp. 631-674 in: Hydrous Phyllosilicates (exclusive of Micas) (S.W. Bailey, editor). Reviews in Mineralogy 19. Mineralogical Society of America, Washington, D.C.

Mifsud A., Routureau M. \& Fornes V. (1978) Etude de l'eau dans la palygorskite a l'aide des analyses thermiques. Clay Minerals, 13, 367-374.

Moore D.M., Robert C. \& Reynolds J.R. (1989) X-ray Diffraction and the Identification and Analysis of Clay Minerals. Oxford University Press, New York.

Nagy B.S. \& Bradley W.F. (1955) The structural scheme of sepiolite (Utah). American Mineralogist, 40, 885-892.

Newman A.C.D. \& Brown G. (1987) The chemical constitution of clays. Pp. 1-129 in: Chemistry of Clays and Clay Minerals (A.C.D. Newman, editor). Monograph 6, Mineralogical Society, London.

Serna C., Van Scoyoc G.E. \& Ahlrichs J.L. (1977) Hydroxyl groups and water in palygorskite. American Mineralogist, 62, 784-792.

Suárez M. \& García-Romero E. (2006a) Macroscopic palygorskite from Volcanic Complex of Lisbom. European Journal of Mineralogy, 18, 119-126.

Suárez M. \& García-Romero E. (2006b) FTIR spectroscopic study of palygorskite: Influence of the composition of the octahedral sheet. Applied Clay Science, 31, 154-163. 